\title{
Article
}

\section{Is the Synthetic Fungicide Fosetyl-Al Safe for the Ecotoxicological Models Danio rerio and Enchytraeus crypticus?}

\author{
Angela Barreto $^{+}\left(\mathbb{D}\right.$, Joana Santos ${ }^{+}(\mathbb{D}$, Mónica J. B. Amorim $(\mathbb{D}$ and Vera L. Maria *(D) \\ Department of Biology \& CESAM, University of Aveiro, 3810-193 Aveiro, Portugal; abarreto@ua.pt (A.B.); \\ joanasilvasantos@ua.pt (J.S.); mjamorim@ua.pt (M.J.B.A.) \\ * Correspondence: vmaria@ua.pt; Tel.: +351-234-370-350; Fax: +351-234-372-587 \\ + Equal first authors-Angela Barreto and Joana Santos.
}

check for updates

Citation: Barreto, A.; Santos, J.; Amorim, M.J.B.; Maria, V.L. Is the Synthetic Fungicide Fosetyl-Al Safe for the Ecotoxicological Models Danio rerio and Enchytraeus crypticus? Appl. Sci. 2021, 11, 7209. https://doi.org/ 10.3390/app11167209

Academic Editor: Marco F. L. Lemos

Received: 8 July 2021

Accepted: 3 August 2021

Published: 5 August 2021

Publisher's Note: MDPI stays neutral with regard to jurisdictional claims in published maps and institutional affiliations.

Copyright: (c) 2021 by the authors. Licensee MDPI, Basel, Switzerland. This article is an open access article distributed under the terms and conditions of the Creative Commons Attribution (CC BY) license (https:/ / creativecommons.org/licenses/by/ $4.0 /)$.

\begin{abstract}
Worldwide, pesticides have contaminated the environment, affecting non-target species. The aim of this work was to evaluate the effects of fosetyl-Al (FOS) on model organisms. Based on the 3 Rs for animal research and described guidelines, the OECD 236 and 220 were applied with some modifications. The FOS test concentrations were $0.02-0.2-2-20-200 \mathrm{mg} / \mathrm{L}$ for Danio rerio and 250-500-750-1000-1250 mg/kg for Enchytraeus crypticus. Besides the standard endpoints, additional endpoints were evaluated (D. rerio: behavior and biochemical responses; E. crypticus: extension of exposure duration ( $28 \mathrm{~d}$ (days) $+28 \mathrm{~d}$ ) and organisms' sizes). For D. rerio, after $96 \mathrm{~h}(\mathrm{~h})$, hatching was inhibited (200 mg/L), proteins' content increased (2 and $20 \mathrm{mg} / \mathrm{L})$, lipids' content decreased $(2 \mathrm{mg} / \mathrm{L})$, glutathione $S$-transferase activity increased $(2 \mathrm{mg} / \mathrm{L})$, and, after $120 \mathrm{~h}$, larvae distance swam increased $(20 \mathrm{mg} / \mathrm{L})$. For E. crypticus, after $28 \mathrm{~d}$, almost all the tested concentrations enlarged the organisms' sizes and, after $56 \mathrm{~d}, 1250 \mathrm{mg} / \mathrm{kg}$ decreased the reproduction. In general, alterations in the organisms' biochemical responses, behavior, and growth occurred at lower concentrations than the effects observed at the standard endpoints. This ecotoxicological assessment showed that FOS may not be considered safe for the tested species, only at higher concentrations than the predicted environmental concentrations (PECs). This research highlighted the importance of a multi-endpoint approach to assess the (eco)toxic effects of the contaminants.
\end{abstract}

Keywords: pesticides; soil and freshwater organisms; reproduction; survival; embryo development; biochemical and behavior biomarkers

\section{Introduction}

Despite the worldwide aim being driven toward more sustainable agriculture, pest management clearly depends on the usage of diverse kinds of pesticides. In Europe, around 380,000 tons of synthetic and inorganic pesticides are sold per year (average between 2011 and 2017 considering 28 European countries) [1,2]. Fungicides are extensively used to control or eradicate fungal phytopathogens. Nevertheless, fungicides employed on soils not only affect the target phytopathogens, but also the non-target autochthonous soil organisms, which have crucial functions in the terrestrial ecosystems [3]. Indeed, pesticides and their transformation products or metabolites may continue in the environment $[2,4]$, contaminating soil and water $[2,5]$ and affecting non-target terrestrial and aquatic organisms [2,6-8], representing a risk for human health $[2,9]$.

Based on the European Food Safety Authority (EFSA), fosetyl-Al (FOS) is one of the active substances listed in Regulation (EU) No 686/2012 [10]. FOS that is sold under the trade name Aliette is an inorganic phosphorous systemic fungicide applied to control various plant pathogenic phycomycetes and ascomycetes, damping off and rotting of plant roots, stems, and fruit. This active substance is utilized for the prevention of crops and for the inhibition of fungal spore propagation and infiltration of pathogens into plants. It is applied as a plant dip treatment and a drench for transplants by incorporating it into the soil prior to planting and by applying it to foliage [11]. A dose of $2.5 \mathrm{~g} / \mathrm{L} \mathrm{FOS} \mathrm{is}$ 
recommended to apply on foliage against fungi that affect several crops, such as citrus, lettuce, and hops [11]. According to EFSA (2018) [10], FOS is a phosphonate compound; its structure and mode of action vary from most of the organophosphorus compounds applied as pesticides. EFSA also reported a data gap for the FOS risk to aquatic organisms and to non-target terrestrial plants.

There is no information regarding the lethal and sub-lethal effects of FOS on the ecotoxicological model aquatic and terrestrial species, Danio rerio and Enchytraeus crypticus, respectively. Considering the effects of other pesticides to $D$. rerio, a median lethal concentration $\left(\mathrm{LC}_{50}\right)$ of $0.235 \mathrm{mg} / \mathrm{L}$, a decreased hatching success, and several malformations were found on embryos after exposure to the insecticide sumithion [12]. Additionally, a strong inhibition of hatching by triazole fungicides [13] and diazinon insecticide [14] exposure was already reported in zebrafish embryos. For E. crypticus, organisms were not affected by the insecticide toxaphene [15] and fungicide prosaro [16]. However, the insecticide dimethoate increased the survival and limited the growth of enchytraeids, and fungicides mancozeb and amistar decreased the survival and reproduction [16,17].

Zebrafish (D. rerio) is a widely used model organism for aquatic (eco)toxicology being employed for the assessment of effects at different levels of biological organization [18]. Particularly, the fish embryo toxicity (FET) test with zebrafish embryos has been shown to be a valuable alternative to the common fish toxicity test [19]. The FET test [20] may be seen as a refinement or even a potential replacement of animal experiments according to the 3 Rs principle (refinement, reduction, and replacement) [21], as the embryos are assumed to experience less or no pain compared to adult fish. In specific, zebrafish was already employed to assess the toxicity of several pesticides, such as imidacloprid, atrazine, chlorpyrifos, butachlor, $\lambda$-cyhalothrin, sumithion, linuron, and propamocarb $[12,18,22,23]$. Enchytraeids are ecologically important, soil-dwelling annelids, playing an essential role in organic matter decomposition and soil bioturbation [24]. Enchytraeid reproduction test (ERT) guidelines [25] have been established for the genus Enchytraeus. E. crypticus gained growing attention in soil ecotoxicological studies due to practical advantages: (1) Is cultured in agar medium, (2) has a high reproductive rate, (3) relatively short generation time and test period, and (4) wider tolerance range to different soil properties $(\mathrm{pH}$, texture, and organic matter content) [24]. Several studies already showed that E. crypticus is a valuable bioindicator of contaminated environments from a large range of anthropogenic sources, including pesticides $[15-17,26]$.

Therefore, the current research was developed to know and describe the potential toxicological effects of FOS on these two models for freshwater and soil ecosystems, $D$. rerio embryos and E. crypticus, respectively. A multi-endpoint approach, including standard (described on the guidelines) and additional endpoints, was performed to reach a more complete evaluation of the potential toxicity of FOS. For E. crypticus, survival, reproduction, and organisms' sizes were evaluated after 28 days (d) of exposure. Moreover, the exposure duration was extended (plus $28 \mathrm{~d}$ ) to evaluate the FOS effects on the organisms' reproduction after $56 \mathrm{~d}$. For D. rerio, after $96 \mathrm{~h}$ (h) of exposure, survival, hatching, development malformations, heartbeat rate, and biochemical responses involved in energy budgets, antioxidants, and neurotoxicity were analyzed. After $120 \mathrm{~h}$, the larvae locomotor behavior was also assessed.

\section{Material and Methods}

\subsection{Test Chemical: Fosetyl-Al (FOS)}

FOS used on the present study was fabricated by LGC Labor GmbH, Germany (CAS number: $39148-24)$ with a purity of $88.90 \%(\mathrm{~g} / \mathrm{g})$ and acquired as a wettable powder. It has the molecular formula of $3 \mathrm{C}_{2} \mathrm{H}_{6} \mathrm{O}_{3}$ P.Al.

\subsection{Test Species: Danio rerio and Enchytraeus crypticus}

Two biological model organisms were used for the bioassays. 
Danio rerio (zebrafish-Cyprinidae, Teleostei) eggs were obtained from a culture maintained at the Department of Biology, University of Aveiro (Aveiro, Portugal). The Zebrafish Facility complies with the Portuguese law (Portaria 1005/02 and Portaria 1131/97), which follows the European Guideline 86/609/EC and conforms with the Council Regulation (EC) No. 2005/01 EC regarding animal transit. It also follows the FELASA (Federation of European Laboratory Animal Science Associations) guidelines and recommendations concerning animal welfare in the care and use of laboratory animals, and in the design and conduct of research projects in which animals are used (including the proper education and training of the people involved in all animal work). Zebrafish adults were kept in a recirculating system with reverse osmosis and activated carbon-filtered tap water, supplemented with instant ocean synthetic salt automatically adjusted for $\mathrm{pH}$ and conductivity. The fish were maintained at $27 \pm 1^{\circ} \mathrm{C}$, under a 12:12 h light:dark photoperiod, with conductivity at $750 \pm 50 \mu \mathrm{S} / \mathrm{cm}, \mathrm{pH}$ at $7.5 \pm 0.5$, salinity of 0.35 , and dissolved oxygen at $95 \%$ saturation. Adult fish were fed daily with a commercial, artificial diet Gemma Micro 500 (Skretting ${ }^{\circledR}$, Burgos, Spain). Reproduction groups were placed in a sloping breeding tank on the day before the test (at $4 \mathrm{pm}$ ). In the next morning, two hours after the opening of the illumination, the eggs were collected, counted and cleaned of residues. Zebrafish eggs with normal development ( $3 \mathrm{~h}$ post-fertilization (hpf)) were chosen for the bioassay, using a Stereoscopic Zoom Microscope-SMZ 1500 (Nikon, Amsterdam, The Netherlands). Unfertilized, irregular, or damaged eggs were rejected.

Enchytraeus crypticus (potworms-Enchytraeidae, Oligochaeta) was also used for the bioassays. E. crypticus adults were obtained from laboratorial cultures maintained at CESAM, University of Aveiro (Aveiro, Portugal). The organisms were kept in agar, consisting of Bacti-Agar medium (Agar No. 1, Lab M Limited, Lancashire, UK) and a mixture of four salt solutions $\left(2 \mathrm{mM} \mathrm{CaCl}_{2} \cdot 2 \mathrm{H}_{2} \mathrm{O}, 1 \mathrm{mM} \mathrm{MgSO}_{4}, 0.08 \mathrm{mM} \mathrm{KCl}\right.$, and $0.75 \mathrm{mM} \mathrm{NaHCO} 3$ ) at $20 \pm 1{ }^{\circ} \mathrm{C}$, under a 16:8 h light:dark photoperiod. Organisms were fed ground, autoclaved oats twice per week. For the bioassay, synchronized-age cultures of E. crypticus were set by transferring, from the laboratorial cultures, adults with welldeveloped clitellum into fresh agar plates to lay cocoons. The number of adults to transfer should be $2 \frac{1}{2}$ times the number of cocoons necessary. After $2 \mathrm{~d}$, cocoons were relocated to fresh agar plates. Juveniles of 17-19 d were used. According to Directive 2010/63/EU of the European Parliament and of the Council of 22 September 2010, invertebrates (like E. crypticus) are allowed biological models for scientific experimentation and are free of an Ethical Statement.

\subsection{Bioassays}

\subsubsection{Danio rerio}

Fish Embryo Acute Toxicity (FET) Test

The FET test was based on the Organization for Economic Co-operation and Development (OECD) guideline number 236 [20]. The selected embryos were distributed in 24-well plates, each well containing one embryo per $2 \mathrm{~mL}$ of the test solution. Twenty replicates $(n=20)$ were used per each experimental condition. Zebrafish embryos were exposed to $0,0.02,0.2,2,20$, and $200 \mathrm{mg} / \mathrm{L}$ of FOS and kept at $27 \pm 1{ }^{\circ} \mathrm{C}$ and a $12: 12 \mathrm{~h}$ light:dark photoperiod. The FOS concentration range was based on 10-fold increases, from the predicted environmental concentrations (PECs) in surface water described by EFSA [10]. FOS, at the tested concentrations, easily dissolved in the zebrafish water; therefore, it was not necessarily a solvent. The test ran at a static system for $96 \mathrm{~h}$ and embryos were observed daily with Stereoscopic Zoom Microscope (SMZ 1500, Nikon) to evaluate the survival, hatching, and the appearance of malformations (in specific, pericardial edema, yolk-sac edema, notochord curvature, loss of equilibrium, and abnormal pigmentation). The lack of heartbeat was checked daily from 48 and $96 \mathrm{~h}$ and the heartbeat rate was evaluated at $48 \mathrm{~h}$. The number of heartbeats per embryo was counted for $30 \mathrm{~s}$ using a mechanical counter. The heartbeat rate (number of heartbeats/minute) was evaluated at $48 \mathrm{~h}$ because at this 
time embryos are in a favorable stage of development and a good position (lateral position) to allow an accurate heartbeat rate evaluation.

\section{Locomotor Behavior Assay}

The FET test exposure was extended until $120 \mathrm{~h}$ and larvae locomotor behavior was analyzed using the Zebrabox tracking system (Viewpoint, Lyon, France) over a period of $12 \mathrm{~min}$. Dead larvae or larvae exhibiting malformations were not included in this assay. Ten replicates $(n=10)$ were used per each experimental condition. The temperature was maintained at $27 \pm 1{ }^{\circ} \mathrm{C}$ and larvae movement was stimulated by alternating light and dark periods. The test consisted of a cycle with two periods: $6 \mathrm{~min}$ of light and $6 \mathrm{~min}$ of darkness. The larvae total time and distance swimming were recorded for each period. Larvae path angle was also calculated through the vector of fish swimming direction and the turn path performed by the organisms. The angles of movements were organized in four classes [27]: Class 1 included big amplitude angles $\left(90-180^{\circ}\right)$, classes 2 and 3 included medium amplitude angles (30-90 and $10-30^{\circ}$, respectively), and class 4 included small amplitude angles $\left(0-10^{\circ}\right)$. Three types of movements were considered: no movements (NM, $0 \mathrm{~mm} / \mathrm{s}$ ), medium-velocity movements (MVM, between 0 and $10 \mathrm{~mm} / \mathrm{s}$ ), and high-velocity movements (HVM, above $10 \mathrm{~mm} / \mathrm{s}$ ).

\section{Biochemical Markers' Assessment}

Based on the results from the FET test, embryos were exposed to 2 and $20 \mathrm{mg} / \mathrm{L}$ of FOS. Seven replicates $(n=7)$ of 15 embryos each were used per experimental condition and kept in Petri dishes at $27 \pm 1{ }^{\circ} \mathrm{C}$. After $96 \mathrm{~h}$ of exposure, the embryos were frozen in liquid nitrogen and stored at $-80^{\circ} \mathrm{C}$ until further analyses. Samples were homogenized in ultrapure water, on ice, using an ultrasonic homogenizer (Sonifier 250, Branson sonicator). The homogenates were divided for the biochemical analyses: total glutathione (TG) content, catalase (CAT) activity, glutathione $S$-transferase (GST) activity, cholinesterase (ChE) activity, protein quantification, and energy budgets. Phosphate buffer (0.2 M; pH 7.4) was added to the homogenate aliquots reserved to TG, CAT, GST, and CHE, which were then centrifuged $\left(10,000 \times g ; 20 \mathrm{~min} ; 4^{\circ} \mathrm{C}\right)$ to obtain the post-mitochondrial supernatant (PMS). A Labsystem Multiskan EX microplate reader was utilized for all the biochemical determinations. TG content was assessed based on the method of Tietze (1969) [28]. CAT activity was measured according to Claiborne (1985) [29]. The measurement of GST activity was performed following the method of Habig et al. (1974) [30]. The measurement of ChE activity was achieved following the protocol defined by Ellman et al. (1961) [31], adapted to a 96-well microplate by Guilhermino et al. (1996) [32]. The quantification of the protein was done following the Bradford method [33], adapted to a 96-well microplate, using bovine $\gamma$-globulin as a standard. The energy budgets (lipids', carbohydrates', and proteins' contents) were measured following De Coen and Janssen (1997) [34], with minor modifications for 96-well microplate reading [35].

\subsubsection{Enchytraeus crypticus}

Enchytraeid Reproduction Test (ERT)

For the ERT, the natural standard LUFA 2.2 soil (Speyer, Germany) was used, with the following main characteristics: $\mathrm{pH}\left(0.01 \mathrm{M} \mathrm{CaCl}_{2}\right)=5.8$; organic carbon $=1.71 \%$; cation exchange capacity $=9.2 \mathrm{meq} / 100 \mathrm{~g}$; maximum water holding capacity $(\mathrm{WHC})=44.8 \%$; grain size distribution of $7.2 \%$ clay, $8 \%$ silt, and $77.5 \%$ sand.

The soil was dried $\left(48 \mathrm{~h} ; 60^{\circ} \mathrm{C}\right)$ prior to use. The control soil $(0 \mathrm{mg}$ FOS $/ \mathrm{kg}$ soil) was prepared by adding deionized water to correct the moisture content $(50 \%$ of the WHC maximum). Concerning FOS treatments, the aqueous solutions of the fungicide were added to the pre-moistened soil considering $50 \%$ of the WHC maximum and mixed manually [25]. Tests started $1 \mathrm{~d}$ after soil spiking. The following FOS nominal concentrations: 250, 500, 750,1000 , and $1250 \mathrm{mg} / \mathrm{kg}$ were considered for soil spiking. These concentrations were selected based on the recommended dose for FOS application (2.5 g/L) [11]. 
The ERT procedures followed the OECD 220 guideline [25] with some adaptations [36]. Briefly, 10 synchronized-age E. crypticus were introduced in each test container (diameter of $4 \mathrm{~cm}$ ) with $20 \mathrm{~g}$ of moist soil and food supply ( $24 \pm 1 \mathrm{mg}$ autoclaved oats). The test ran for $28 \mathrm{~d}$ at $20 \pm 1{ }^{\circ} \mathrm{C}$ and a 16:8-h light:dark photoperiod. During the test, food (24 $\pm 1 \mathrm{mg}$ autoclaved oats) and water content (based on weight loss) were replenished weekly. Per experimental conditions, four replicates were used $(n=4)$. An extra replicate per experimental condition (without organisms) was included to measure the $\mathrm{pH}$ values. At the end of the test period, the E. crypticus were fixed with ethanol and stained with Bengal rose ( $1 \%$ in ethanol). After $24 \mathrm{~h}$, soil samples were sieved through meshes with decreasing pore size $(1.6,0.5$, and $0.3 \mathrm{~mm})$ to separate the organisms from most of the soil and facilitate counting. For survival and reproduction evaluation, adult and juvenile enchytraeids were counted, respectively, using a stereomicroscope. For the exposure extension of $28 \mathrm{~d}$ (i.e., $56 \mathrm{~d}$ ), four extra replicates $(n=4)$ were done and, hence, larger test containers (diameter of $5.5 \mathrm{~cm}$ ) were utilized, with $40 \mathrm{~g}$ of soil per replicate because of the expected higher density of organisms. For these replicates, at day 28 , adults (the original synchronized-age juveniles) were carefully removed from the soil, after which the soil was left, replenishing water and food ( $24 \pm 1 \mathrm{mg}$ autoclaved oats) weekly. At $56 \mathrm{~d}$, the number of juveniles was assessed, as performed at $28 \mathrm{~d}$. The size (length) of the adults (i.e., the 10 synchronized-age organisms) collected at day 28 was also evaluated.

\subsection{Data Analysis}

Graphics and statistical analyses were performed using the Sigma Plot 12.5 software package. Shapiro-Wilk and Levene's tests were performed to evaluate the normality and homoscedasticity of data, respectively. One-way analysis of variance (ANOVA) followed by Dunnett's multiple comparison post hoc test was applied to assess differences between control and FOS treatments. When data failed the normality and/or homoscedasticity tests, a non-parametric Kruskal-Wallis test was applied. Significant differences were considered for $p<0.05$.

\section{Results and Discussion}

\subsection{Danio rerio}

\subsubsection{Fish Embryo Acute Toxicity (FET) Test}

FOS caused no significant effects on the organisms' survival during $96 \mathrm{~h}$ of exposure $(p>0.05$, Figure 1A). In terms of hatching, organisms did not hatch at $200 \mathrm{mg} / \mathrm{L} \mathrm{FOS}$ $(p<0.05$, Figure 1B). FOS did not cause significant malformations' induction and did not affect the heartbeat rate $(p>0.05$, Figure 1C,D).

Based on the mentioned results, FOS showed low toxicity to zebrafish embryos. No study was found about the effects of FOS to zebrafish. A LC 50 of $428 \mathrm{mg} / \mathrm{L}$ was reported for the fish rainbow trout after $96 \mathrm{~h}$ exposure to FOS [37]. FOS has a period for $50 \%$ dispersion $\left(\mathrm{DT}_{50}\right)$ of $3 \mathrm{~d}$ in surface waters [10]. Thus, the obtained effects on hatching may be mainly due to the parental compound FOS and not its metabolites: phosphonic acid and ethanol. A $20 \%$ effect concentration $\left(\mathrm{EC}_{20}\right)$ to hatching of Pimephales promelas was determined as $0.44 \mathrm{mg}$ of active substance (FOS WG80 of Bayer CropScience)/L, for a chronic exposure [10]. Comparing both freshwater fish (P. promelas versus D. rerio), the fungicide FOS WG80 was more toxic than the FOS used in the current study. Based on the literature, EFSA (2018) considered FOS as a compound with lower acute/chronic risk to aquatic organisms [10]. Regarding FOS metabolites' effects, in a study using disodium phosphonate (related to phosphonic acid), a LC $50>61.26 \mathrm{mg} / \mathrm{L}$ for Daphnia magna ( $48 \mathrm{~h}$, static exposure) was calculated [38], which showed a greater (severe) effect in comparison to the parental compound (FOS).

Considering the effects of other pesticides to zebrafish embryos, a $\mathrm{LC}_{50}$ of $0.235 \mathrm{mg} / \mathrm{L}$ was found after $24 \mathrm{~h}$ exposure to sumithion [12]. Increasing sumithion concentrations also decreased hatching success and induced several malformations on the organisms [12]. Triazole fungicides [13] and the insecticide diazinon [14] induced a strong inhibition of 
hatching in zebrafish embryos. From five tested pesticides, chlorpyrifos, $\lambda$-cyhalothrin, and butachlor had the highest toxicities to $D$. rerio with a $L_{50}$ value ranging from 0.28 to $0.45 \mathrm{mg} / \mathrm{L}$ [22]. Comparing the results from studies including other pesticides [12,22] with the ones found in our study (malformations, heartbeat, hatching, and survival), FOS induced less toxicity for zebrafish embryos than the other referred pesticides.
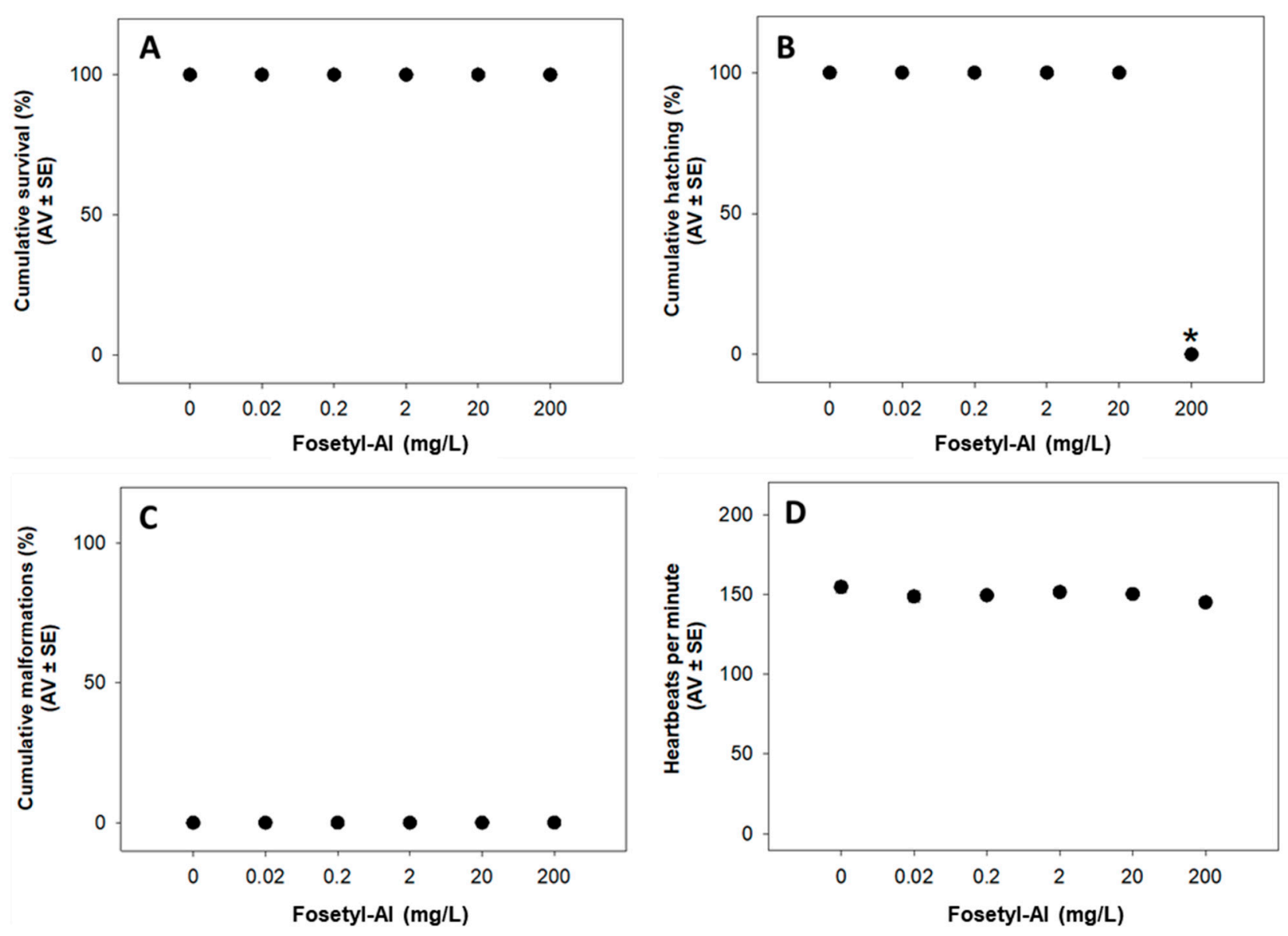

Figure 1. Effects of $96 \mathrm{~h}$ of exposure to fosetyl-Al on zebrafish embryos for survival (A); hatching (B); appearance of malformations (C); and heartbeat at $48 \mathrm{~h}(\mathrm{D})$. Data are expressed as average value (AV) \pm standard error (SE). ${ }^{*}$ Significant differences to control $(p<0.05)$.

The organisms' hatching occurs from the activity of the hatching enzyme chorinase, muscle contraction, perivitelline pressure, and water uptake by the embryo [14]. FOS may disturb directly these processes, e.g., through the inhibition of the chorinase or less energy could be available for hatching since exposed organisms assign part of their energy to metabolic pathways for FOS elimination. Inhibition of hatching is generally classified as a sub-lethal effect; however, it can result in death or delay in the organism development/maturation if it is not reversed in a short term. Thus, hatching inhibition may cause a negative impact at the population level. There is a data gap concerning the involvement of hormones in the hypothesized mode of action of FOS as an endocrine disruptor. A study using a mixture of fungicides (without FOS) showed impairments in the reproductive performance of Hyalella azteca (amphipod) [39]. It will be important to explore this issue, applying a multigenerational approach where multi-level hierarchical responses can be elucidated (e.g., at molecular, biochemical, and population level).

\subsubsection{Locomotor Behavior Assay}

Zebrafish larvae typically present low levels of activity during light and increase their locomotor activity upon a sudden switch to darkness. Thus, only the data obtained 
during the 6-min dark period were analyzed and will be shown. The organisms exposed to $200 \mathrm{mg} / \mathrm{L}$ of FOS did not hatch; therefore, it was not possible to assess the locomotor behavior. After $120 \mathrm{~h}$, FOS induced no effect in terms of total swimming time $(p>0.05$, Figure 2A); however, $20 \mathrm{mg} / \mathrm{L}$ FOS increased the distance swam by zebrafish larvae $(p<0.05$, Figure 2B). Larvae path angle and types of movement were not altered by FOS exposure comparing with the control group $(p>0.05$, Figure $2 \mathrm{C}, \mathrm{D})$. Considering other pesticides, pendimethalin, diazinon, hexazinone, methomyl, molinate, and dimethoate decreased the distance moved by zebrafish larvae [40]. However, other pesticides (paraquat and amitrole) increased the distance moved by larvae [40], as found in our study. In fact, even at low concentrations, neurobehavioral toxicity of different pesticides, including organophosphates, to non-target organisms are very well documented [41,42]. These effects can be, in most cases, severe, for long periods, or irreversible. Moreover, it can be more adverse during early development of the organisms [42]. The detected increased total distance that was moved by larvae at $20 \mathrm{mg} / \mathrm{L}$ of FOS suggests hyperactivity. FOS may be metabolized to phosphorous acid, interfering with ATP synthesis $[43,44]$. The effects on fish larvae locomotion behavior may be relevant in some ecological functions of the organisms, such as feeding, reproduction, and escaping from predators [45]. However, the effects detected in the current study for larvae locomotor behavior (at $20 \mathrm{mg} / \mathrm{L}$ ) are not at PECs.
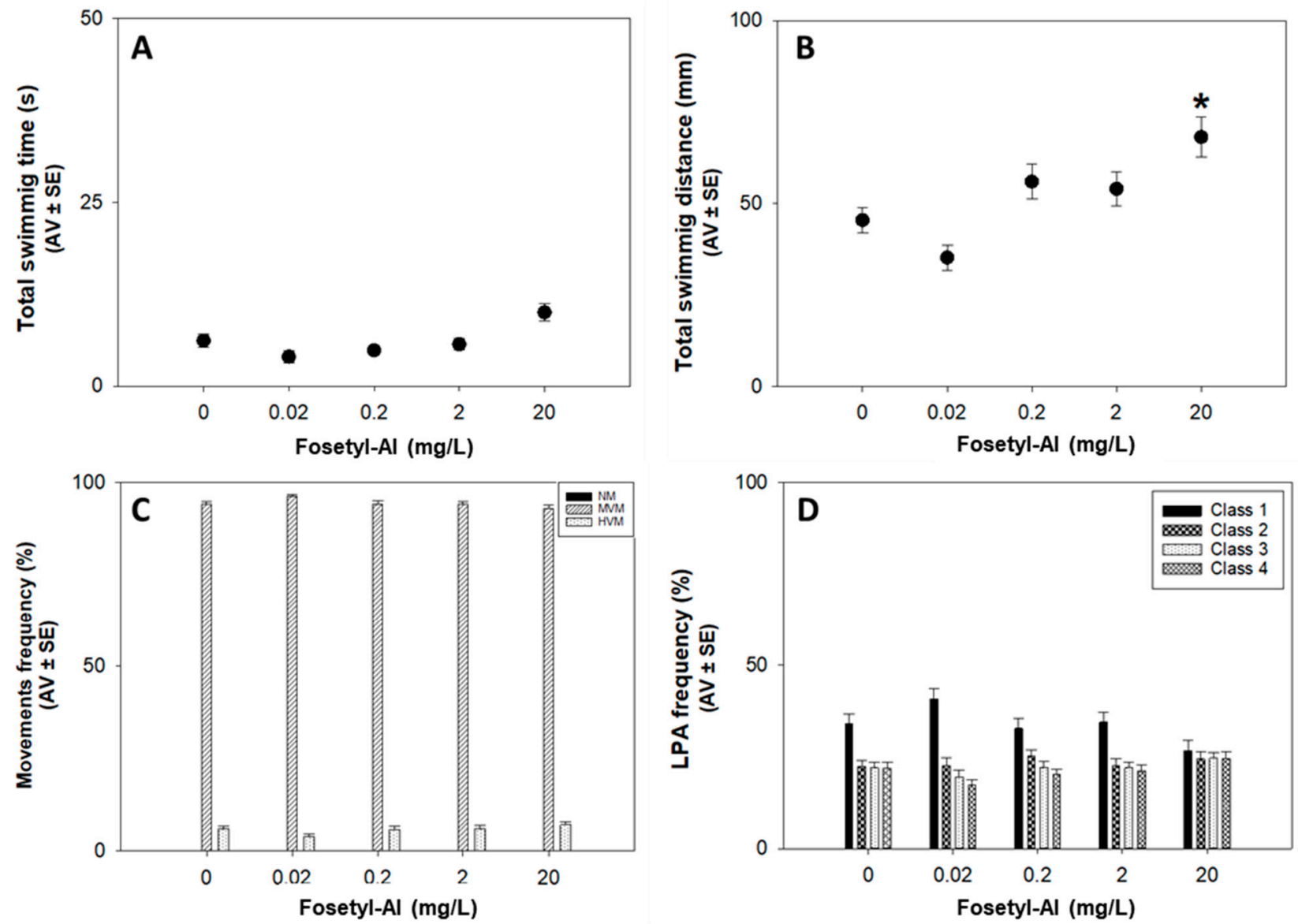

Figure 2. Effects of $120 \mathrm{~h}$ of exposure to fosetyl-Al on zebrafish larvae for total swimming time (A) and distance (B); types of movements (C); and larvae path angle (LPA) (D). NM, no movements; MVM, medium-velocity movements; HVM, high-velocity movements. Class 1: big amplitude angles (90-180 ); Class 2: medium amplitude angles (30-90 $)$; Class 3: medium amplitude angles $\left(10-30^{\circ}\right)$; Class 4 : small amplitude angles $\left(0-10^{\circ}\right)$. Data are expressed as average value $(\mathrm{AV}) \pm$ standard error $(\mathrm{SE}) .{ }^{*}$ Significant differences to control $(p<0.05)$. 


\subsubsection{Biochemical Markers}

After $96 \mathrm{~h}$, FOS did not cause any significant variation in the glycogen content of zebrafish larvae ( $p>0.05$, Figure $3 \mathrm{~A})$; however, the proteins content increased at 2 and $20 \mathrm{mg} / \mathrm{L}$ FOS ( $p<0.05$, Figure 3B) and a decrease in lipids content was found at $2 \mathrm{mg} / \mathrm{L}$ FOS $(p<0.05$, Figure 3 C). Contaminants may change the total energy available on the organisms, which originates compensatory corrections in the energy metabolism to keep the homeostasis [46]. Lipids are considered the primary energy source mobilized when organisms are exposed to contaminants and, with the carbohydrates, they are rapidly mobilized to supply a sudden energy demand while proteins are the last choice of energy source, being usually mobilized only under severe conditions [46]. Decreased lipid contents may be a result of physiological stress response caused by FOS [47]. The detected effects on energy metabolism of zebrafish embryos after FOS exposure (increased protein content and decreased lipids' content) may compromise other biological functions, such as growth, reproduction, development, and locomotor activity. In our study, no effects were found on zebrafish development (e.g., in terms of hatching, heartbeat rate, and malformations appearance) by 2 and $20 \mathrm{mg} / \mathrm{L}$ FOS. However, an increase in the distance swam by zebrafish larvae was found to $20 \mathrm{mg} / \mathrm{L}$ FOS, which may be related with the detected alterations on the energy metabolism.
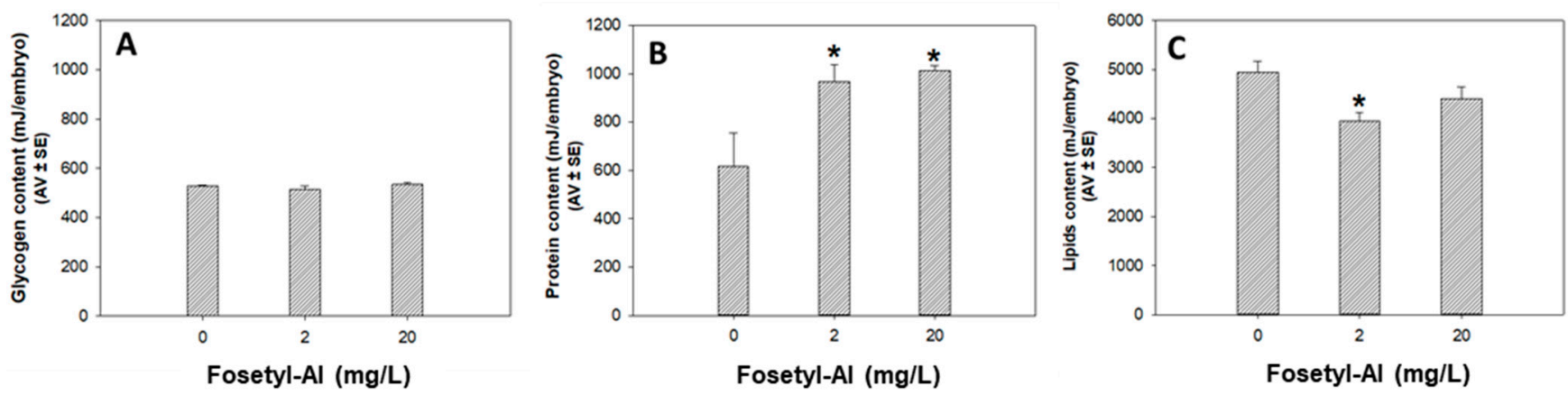

Figure 3. Effects of $96 \mathrm{~h}$ of exposure to fosetyl-Al on zebrafish larvae for carbohydrates' (A); proteins' (B); and lipids' (C) contents. Data are expressed as average value (AV) \pm standard error (SE). ${ }^{*}$ Significant differences to control $(p<0.05)$.

After 96 h, FOS induced no significant effects on ChE, CAT activities, and TG content of zebrafish larvae $(p>0.05$, Figure 4A,C,D). However, FOS ( $2 \mathrm{mg} / \mathrm{L})$ increased GST activity $(p<0.05$, Figure $4 \mathrm{~B})$. Oxidative damage results from an imbalance between oxidants and antioxidant levels in the organism, which increases reactive oxygen species (ROS) generation. ROS may react with biomolecules, such as lipids and proteins, affecting cell viability $[48,49]$. However, fish have effective antioxidant defenses comprised by various antioxidant enzymes (e.g., CAT and GST) and low-molecular-weight scavengers (e.g., glutathione (GSH)) [50-52]. GST is a phase II detoxification family of enzymes and an oxidative stress biomarker. The increased GST activity detected in zebrafish larvae after exposure to FOS may be associated to the elimination of lipid peroxides by GST-conjugated products [49]. GST may not be considered a highly sensitive biomarker regarding organophosphate exposures [17,50,51], but may be useful as a biomarker for long-term exposure scenarios, as it seems that it requires a longer exposure period to inhibit GST by organophosphates $[18,53,54]$. FOS did not also significantly alter the activity of CAT (another oxidative stress-related biomarker). Therefore, the lack of an effect on the tested enzymatic biomarkers could be due to the short time of exposure (96 h) [49]. However, a previous study reported a relevant increase of GSH after $1 \mathrm{~h}$ of exposure of zebrafish larvae to the pesticides diazinon and diuron [18]. Diazinon also caused an inhibition of ChE activity in zebrafish larvae [18]. Indeed, the primary target of organophosphates pesticides is the enzyme acetylcholinesterase (AChE), which hydrolyzes the neurotransmitter acetylcholine in the peripheral and central nervous system [42]. Organophosphates are known to inhibit the activity of $\mathrm{ChE}[18,55]$, whereas, in the current study, no effect was 
detected in the ChE activity after the exposure to FOS, suggesting that FOS may have a distinct mode of action than the organophosphates pesticides. Moreover, the behavioral effects detected in the current study cannot be related to the alterations on ChE activity. A further neurotoxicity study with FOS should be provided to comprehend its role on the nervous system of non-target organisms.
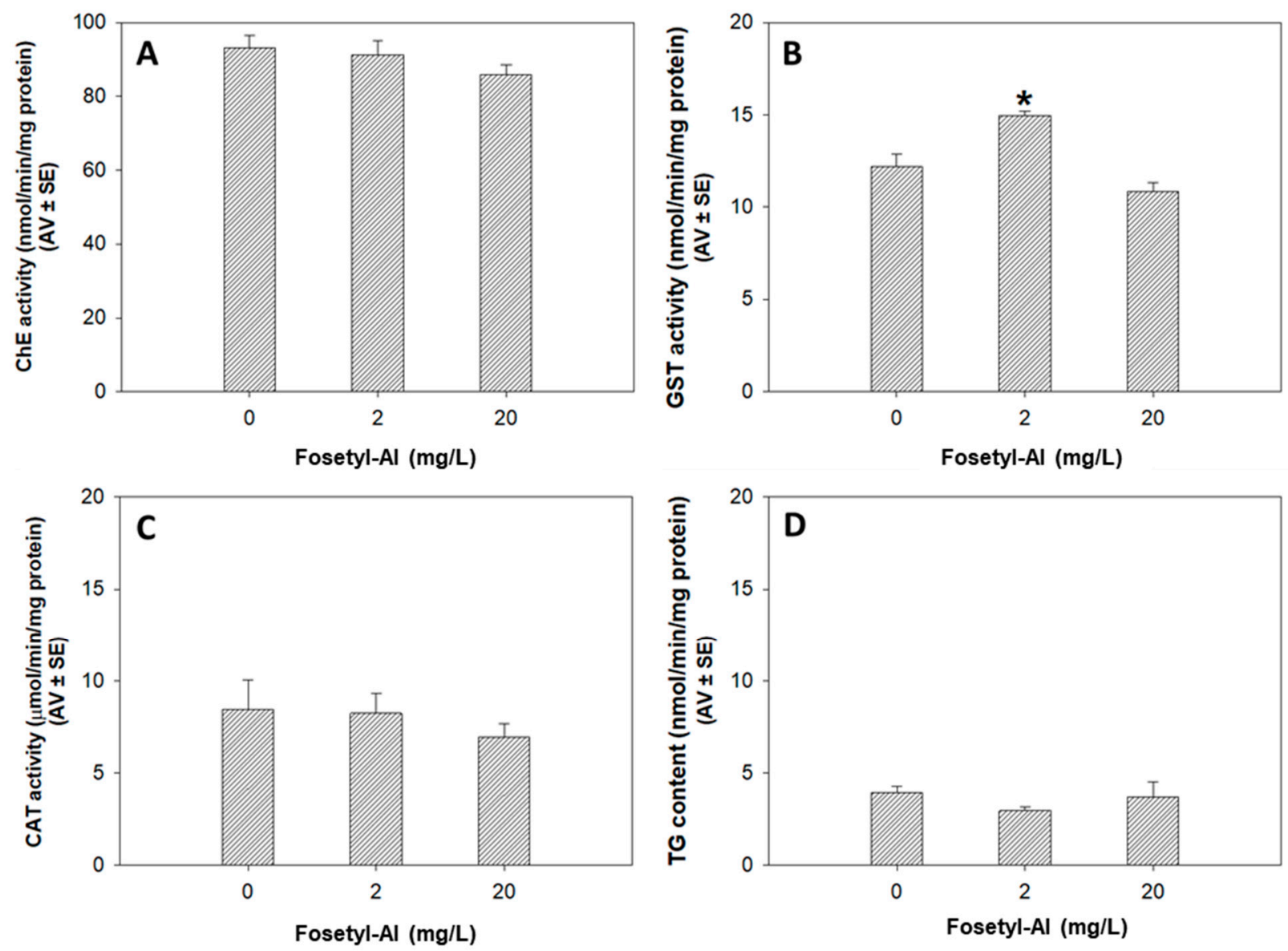

Figure 4. Effects of $96 \mathrm{~h}$ pf exposure to fosetyl-Al on zebrafish larvae for cholinesterase (ChE) (A); glutathione S-transferase (GST) (B); catalase (CAT) (C) activities; and total glutathione (TG) content (D). Data are expressed as average value $(\mathrm{AV}) \pm$ standard error $(\mathrm{SE}) .{ }^{*}$ Significant differences to control $(p<0.05)$.

\subsection{Enchytraeus crypticus}

Enchytraeid Reproduction Test (ERT)

FOS induced no effects in terms of survival and reproduction of E. crypticus after $28 \mathrm{~d}$ of exposure ( $p>0.05$, Figure $5 \mathrm{~A})$. However, a decrease in the population number after $56 \mathrm{~d}$ was found at $1250 \mathrm{mg} / \mathrm{kg}$ FOS ( $p<0.05$, Figure $5 \mathrm{~B}$ ). The toxicity of FOS to E. crypticus seems to have increased with the increase of the exposure period. This corroborates the idea that, for some endpoints (in this case reproduction), FOS seems to have a toxicological action analogous to the organophosphates, since it only caused toxic effects after a longerterm exposure $[18,49,53,54]$. In addition, all the tested concentrations of FOS (except for $500 \mathrm{mg} / \mathrm{kg}$ ) enhanced the size (length) of adults after $28 \mathrm{~d}(p<0.05$, Figure 3C). No study was found about the effects of FOS to E. crypticus. However, for a Folsomia candida chronic exposure with FOS water-dispersible granule containing $800 \mathrm{~g} / \mathrm{kg}$ (WG80) (Bayer CropScience) an $\mathrm{EC}_{20}$ of $958.8 \mathrm{mg} / \mathrm{kg}$ for reproduction was calculated [10]. In soil, FOS can be rapidly transformed to their metabolites, phosphonic acid and ethanol $\left(\mathrm{DT}_{50}=0.1 \mathrm{~d}\right.$ ). Phosphonic acid is an important degradation product of FOS due to its persistence with a $\mathrm{DT}_{50}$ of 28 to $130 \mathrm{~d}$ in soil [10]. Hence, we cannot discard the hypothesis that the 
observed effects in the present study may be due to FOS metabolite, phosphonic acid. A value of $\mathrm{LC}_{50}>615 \mathrm{mg} / \mathrm{kg}$ was estimated for earthworms after acute exposure (14 d) to phosphonic acid [38]. Based on the current data gap, a phosphonic acid risk assessment for soil invertebrates is needed (this is also in line with the Terrestrial Guidance Document from the European Commission) [38].
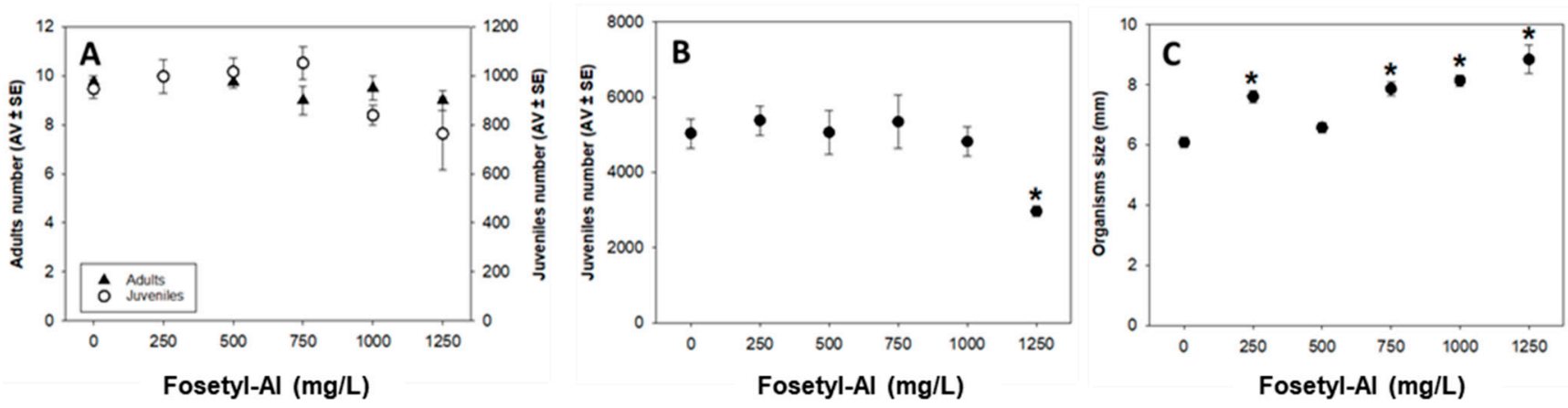

Figure 5. Effects of fosetyl-Al on Enchytraeus crypticus for survival (number of adults) and reproduction (number of juveniles) after $28 \mathrm{~d}$ of exposure (A); reproduction (number of juveniles) after $56 \mathrm{~d}$ of exposure (B); and adults' sizes after $28 \mathrm{~d}$ of exposure (C). Data are expressed as average value (AV) \pm standard error (SE). ${ }^{*}$ Significant differences to control $(p<0.05)$.

For E. crypticus, a recent work with various fungicides showed that $21 \mathrm{~d}$ exposure of prosaro did not also affect reproduction and survival of the organisms [16]. On contrary, another fungicide, amistar, had a toxic effect to E. crypticus, with the reproduction being the most sensitive endpoint [16]. Another study reported that E. crypticus were not affected by the pesticide toxaphene even at the highest tested concentration $(1000 \mathrm{mg} / \mathrm{kg})$ [15] Dimethoate increased the survival and mancozeb decreased the survival and reproduction of enchytraeids [17]. The size of the adults was significantly affected by dimethoate, increasing the dimethoate concentration limited growth [17]. This is an opposite effect considering the one detected in our study: FOS increased the organisms' sizes. Growth is a very relevant ecological endpoint [56]. Effects of the contaminants on the organisms' sizes may induce harmful consequences in terms of organisms' performances, e.g., change in age structure and, hence, population dynamics [57]. The detected increase of size may be a trade-off, i.e., an investment of the organisms in terms of optimal size for their survival, after the exposure to FOS. Indeed, no significant alterations were found on survival of E. crypticus after $28 \mathrm{~d}$ of exposure. It is of interest to note that the increase of adults' sizes in the first generation (as mentioned, probably an investment for survival) did not prevent the impact on reproduction at $56 \mathrm{~d}$, which was significantly reduced when parents were largest (Figure 5B,C).

\subsection{Integration of Knowledge for Risk Assessment}

The risk assessment of pesticides to non-target organisms usually is based on standard tests. The impact of the contaminants is measured through standard endpoints, such as reproduction and survival. However, these biological responses only give information about the potential ecological impact of the selected contaminant, being the assessment of other endpoints highly recommended [58]. Indeed, data covering a larger spectrum are welcomed, but when it is not possible to obtain detailed answers about the mechanistic issues involved, there is a need to look behind the apical effects. As detected in our study, alterations in terms of biochemical responses, behavior, and growth of the organisms occurred at lower concentrations than the effects observed at the standard endpoints (e.g., hatching and reproduction). Comparing the data obtained with the previously published ones, the mechanisms of toxicity of the pesticides seem dependent on the type of the pesticide and the test organism. Although, for FOS, PECs did not cause toxic effects to the tested organisms, for other pesticides, the effects may be detected at environmentally relevant concentrations. Another important aspect is that the toxicity tests should consider longer 
exposure periods than the ones recommended by the guidelines [59]. In the environment, pesticides (and their metabolites and transformation products) may persist for long periods of time and the organisms may be continuously exposed [57]. Indeed, the toxic effect of FOS (decrease of organisms' reproduction for the highest concentration) was only seen after a long-term exposure ( $56 \mathrm{~d}$ ). This has been the case for other contaminants, e.g., multi-walled carbon nanotubes (MWCNT) [60] or tungsten carbide cobalt (WCCo) [36] materials, where the effects were minute after $28 \mathrm{~d}$ and significantly higher at $56 \mathrm{~d}$.

\section{Conclusions}

Some adverse effects were found after the exposure to FOS (D. rerio: hatching, behavior, and biochemical responses; E. crypticus: reproduction and growth). Answering to the main question of the current study, FOS may not be considered safe for D. rerio and E. crypticus for concentrations higher than the PECs described for soil (e.g., $1.067 \mathrm{mg} / \mathrm{kg}$ ) and for surface water (e.g., $0.06496 \mathrm{mg} / \mathrm{L}$ ). For a better evaluation of the risk, the obtained results showed the importance of assessing the short- and long(er)-term effects of different pesticides and their metabolites (as is the case of phosphonic acid) to various non-target organisms. Additionally, a multi-endpoint approach, with standard (described by the guidelines) and extra endpoints, is highly recommended for further studies. Multigenerational studies might also be required to address the potential endocrine-disrupting properties of FOS and phosphonic acid in non-target organisms (this is a data gap).

Author Contributions: Conceptualization: A.B., J.S. and V.L.M.; methodology: A.B., J.S. and V.L.M.; formal analysis: A.B., J.S. and V.L.M.; investigation: A.B., J.S. and V.L.M.; resources: V.L.M. and M.J.B.A.; writing—original draft preparation: A.B.; writing—review and editing: A.B., J.S., V.L.M. and M.J.B.A.; project administration: V.L.M.; funding acquisition: V.L.M. All authors have read and agreed to the published version of the manuscript.

Funding: This research was funded by the project UNRAvEL (POCI-01-0145-FEDER-029035) financed by FEDER, through COMPETE 2020-POCI, PT 2020, and by national funds (OE), through FCT/MCTES national funds (PIDDAC). FCT/MEC (Fundação para a Ciência e Tecnologia/Ministério da Ciência e Tecnologia e Ensino Superior) did the financial support to CESAM (Centro de Estudos do Ambiente e do Mar) (UIDP/50017/2020+UIDB/50017/2020) via national funds. J. Santos and A. Barreto have a fellowship and a contract researcher from the project (POCI-01-0145-FEDER-029035), respectively. V.L. Maria is funded by national funds (OE), through FCT, in the scope of the framework contract foreseen in the numbers 4, 5, and 6 of the article 23, of the Decree-Law 57/2016, of 29 August, changed by Law $57 / 2017$ of 19 July.

Institutional Review Board Statement: The experiments were in accordance with the current laws of the country in which they were performed. Zebrafish Facility complies with the Portuguese law (Portaria 1005/02 and Portaria 1131/97), which follows the European Guideline 86/609/EC, and with the Council Regulation No. 2005/01 EC. It also follows the FELASA (Federation of European Laboratory Animal Science Associations) guidelines and recommendations concerning animal welfare and the design and conduct of research projects in which animals are used. Animal housing, welfare, and experimentation were under constant monitoring from the veterinary service.

Informed Consent Statement: Not applicable.

Data Availability Statement: The data are available on request from the corresponding author.

Conflicts of Interest: The authors declare no conflict of interest.

\section{References}

1. Chiaia-Hernandez, A.C.; Keller, A.; Wächter, D.; Steinlin, C.; Camenzuli, L.; Hollender, J.; Krauss, M. Long-Term Persistence of Pesticides and TPs in Archived Agricultural Soil Samples and Comparison with Pesticide Application. Environ. Sci. Technol. 2017, 51, 10642-10651. [CrossRef] [PubMed]

2. Fournier, B.; Pereira Dos Santos, S.; Gustavsen, J.A.; Imfeld, G.; Lamy, F.; Mitchell, E.A.D.; Mota, M.; Noll, D.; Planchamp, C.; Heger, T.J. Impact of a synthetic fungicide (fosetyl-Al and propamocarb-hydrochloride) and a biopesticide (Clonostachys rosea) on soil bacterial, fungal, and protist communities. Sci. Total Environ. 2020, 738, 139635. [CrossRef] 
3. Channabasava, A.; Lakshman, H.C.; Jorquera, M.A. Effect of fungicides on association of arbuscular mycorrhiza fungus Rhizophagus fasciculatus and growth of Proso millet (Panicum miliaceum L.). J. Soil Sci. Plant Nutr. 2015, 15, 35-45. [CrossRef]

4. Prashar, P.; Shah, S. Impact of Fertilizers and Pesticides on Soil Microflora in Agriculture. In Sustainable Agriculture Reviews; Lichtfouse, E., Ed.; Springer International Publishing: Cham, Germany, 2016; Volume 19, pp. 331-361, ISBN 978-3-319-26777-7.

5. Vryzas, Z. Pesticide fate in soil-sediment-water environment in relation to contamination preventing actions. Curr. Opin. Environ. Sci. Health 2018, 4, 5-9. [CrossRef]

6. Imfeld, G.; Vuilleumier, S. Measuring the effects of pesticides on bacterial communities in soil: A critical review. Eur. J. Soil Biol. 2012, 49, 22-30. [CrossRef]

7. Pisa, L.W.; Amaral-Rogers, V.; Belzunces, L.P.; Bonmatin, J.M.; Downs, C.A.; Goulson, D.; Kreutzweiser, D.P.; Krupke, C.; Liess, M.; McField, M.; et al. Effects of neonicotinoids and fipronil on non-target invertebrates. Environ. Sci. Pollut. Res. 2015, $22,68-102$. [CrossRef]

8. Beketov, M.A.; Kefford, B.J.; Schäfer, R.B.; Liess, M. Pesticides reduce regional biodiversity of stream invertebrates. Proc. Natl. Acad. Sci. USA 2013, 110, 11039-11043. [CrossRef] [PubMed]

9. Cimino, A.M.; Boyles, A.L.; Thayer, K.A.; Perry, M.J. Effects of Neonicotinoid Pesticide Exposure on Human Health: A Systematic Review. Environ. Health Perspect. 2017, 125, 155-162. [CrossRef] [PubMed]

10. EFSA; Arena, M.; Auteri, D.; Barmaz, S.; Bellisai, G.; Brancato, A.; Brocca, D.; Bura, L.; Byers, H.; Chiusolo, A.; et al. Peer review of the pesticide risk assessment of the active substance phenmedipham. EFSA J. 2018, 16, e05150.

11. Almeida, P.; Coutinho, J.; Rocha, J.; Gomes-Laranjo, J. Study of the effect of Aliette on the activity of spinach (Spinacea oleracea L.) chloroplasts. Braz. J. Plant Physiol. 2007, 19, 77-81. [CrossRef]

12. Rahman, M.S.; Islam, S.M.M.; Haque, A.; Shahjahan, M. Toxicity of the organophosphate insecticide sumithion to embryo and larvae of zebrafish. Toxicol. Rep. 2020, 7, 317-323. [CrossRef]

13. De la Paz, J.F.; Beiza, N.; Paredes-Zúñiga, S.; Hoare, M.S.; Allende, M.L. Triazole Fungicides Inhibit Zebrafish Hatching by Blocking the Secretory Function of Hatching Gland Cells. Int. J. Mol. Sci. 2017, 18, 710. [CrossRef] [PubMed]

14. Osterauer, R.; Köhler, H.-R. Temperature-dependent effects of the pesticides thiacloprid and diazinon on the embryonic development of zebrafish (Danio rerio). Aquat. Toxicol. 2008, 86, 485-494. [CrossRef] [PubMed]

15. Bezchlebová, J.; Černohlávková, J.; Lána, J.; Sochová, I.; Kobetičová, K.; Hofman, J. Effects of toxaphene on soil organisms. Ecotoxicol. Environ. Saf. 2007, 68, 326-334. [CrossRef] [PubMed]

16. Gomes, S.I.L.; Ammendola, A.; Casini, S.; Amorim, M.J.B. Toxicity of fungicides to terrestrial non-target fauna-Formulated products versus active ingredients (azoxystrobin, cyproconazole, prothioconazole, tebuconazole) —A case study with Enchytraeus crypticus (Oligochaeta). Sci. Total Environ. 2021, 754, 142098. [CrossRef]

17. Camargo Carniel, L.S.; Niemeyer, J.C.; Iuñes de Oliveira Filho, L.C.; Alexandre, D.; Gebler, L.; Klauberg-Filho, O. The fungicide mancozeb affects soil invertebrates in two subtropical Brazilian soils. Chemosphere 2019, 232, 180-185. [CrossRef]

18. Velki, M.; Lackmann, C.; Barranco, A.; Ereño Artabe, A.; Rainieri, S.; Hollert, H.; Seiler, T.-B. Pesticides diazinon and diuron increase glutathione levels and affect multixenobiotic resistance activity and biomarker responses in zebrafish (Danio rerio) embryos and larvae. Environ. Sci. Eur. 2019, 31, 4. [CrossRef]

19. Lammer, E.; Carr, G.J.; Wendler, K.; Rawlings, J.M.; Belanger, S.E.; Braunbeck, T. Is the fish embryo toxicity test (FET) with the zebrafish (Danio rerio) a potential alternative for the fish acute toxicity test? Comp. Biochem. Physiol. Part C Toxicol. Pharmacol. 2009, 149, 196-209. [CrossRef]

20. OECD. Test No. 236: Fish Embryo Acute Toxicity (FET) Test; OECD Publishing: Paris, France, 2013. [CrossRef]

21. Kirk, R.G.W. Recovering the Principles of Humane Experimental Technique: The 3Rs and the Human Essence of Animal Research. Sci. Technol. Human Values 2018, 43, 622-648. [CrossRef]

22. Wang, Y.; Yang, G.; Dai, D.; Xu, Z.; Cai, L.; Wang, Q.; Yu, Y. Individual and mixture effects of five agricultural pesticides on zebrafish (Danio rerio) larvae. Environ. Sci. Pollut. Res. 2017, 24, 4528-4536. [CrossRef]

23. Caioni, G.; Merola, C.; Perugini, M.; d'Angelo, M.; Cimini, A.M.; Amorena, M.; Benedetti, E. An Experimental Approach to Study the Effects of Realistic Environmental Mixture of Linuron and Propamocarb on Zebrafish Synaptogenesis. Int. J. Environ. Res. Public Health 2021, 18, 4664. [CrossRef] [PubMed]

24. Castro-Ferreira, M.P.; Roelofs, D.; van Gestel, C.A.M.; Verweij, R.A.; Soares, A.M.V.M.; Amorim, M.J.B. Enchytraeus crypticus as model species in soil ecotoxicology. Chemosphere 2012, 87, 1222-1227. [CrossRef]

25. OECD. Test No. 220: Enchytraeid Reproduction Test; OECD Guidelines for the Testing of Chemicals, Section 2; Organization for Economic Cooperation and Development (OECD): Paris, France, 2016; ISBN 9789264264472.

26. Testa, M.; da Silva, A.S.; Segat, J.C.; Maluche-Baretta, C.R.D.; Baretta, D. Impacts on reproduction of Enchytraeus crypticus in fertilized soils with chicken litter treated with synthetic and natural insecticide. Environ. Toxicol. Pharmacol. 2020, $78,103386$. [CrossRef]

27. Zhang, B.; Chen, X.; Pan, R.; Xu, T.; Zhao, J.; Huang, W.; Liu, Y.; Yin, D. Effects of three different embryonic exposure modes of 2, 2', 4 , 4'-tetrabromodiphenyl ether on the path angle and social activity of zebrafish larvae. Chemosphere 2017, 169, 542-549. [CrossRef]

28. Tietze, F. Enzymic method for quantitative determination of nanogram amounts of total and oxidized glutathione: Applications to mammalian blood and other tissues. Anal. Biochem. 1969, 27, 502-522. [CrossRef] 
29. Clairborne, A. Catalase activity. In Handbook of Methods for Oxygen Radical Research; Greenwald, R.A., Ed.; CRC: Boca Raton, FL, USA, 1985; pp. 283-284.

30. Habig, W.H.; Pabst, M.J.; Jakoby, W.B. Glutathione S-Transferases, The first enzymatic step in mercapturic acid formation. J. Biol. Chem. 1974, 249, 7130-7139. [CrossRef]

31. Ellman, G.L.; Courtney, K.D.; Andres, V.; Featherstone, R.M. A new and rapid colorimetric determination of acetylcholinesterase activity. Biochem. Pharmacol. 1961, 7, 88-95. [CrossRef]

32. Guilhermino, L.; Lopes, M.C.; Carvalho, A.P.; Soares, A.M. Acetylcholinesterase activity in juveniles of Daphnia magna Straus. Bull. Environ. Contam. Toxicol. 1996, 57, 979-985. [CrossRef] [PubMed]

33. Bradford, M.M. A rapid and sensitive method for the quantitation of microgram quantities of protein utilizing the principle of protein-dye binding. Anal. Biochem. 1976, 72, 248-254. [CrossRef]

34. De Coen, W.; Janssen, C.R. The use of biomarkers in Daphnia magna toxicity testing. IV.Cellular Energy Allocation: A new methodology to assess the energy budget of toxicant-stressed Daphnia populations. J. Aquat. Ecosyst. Stress Recover. 1997, 6, 43-55. [CrossRef]

35. Rodrigues, A.C.M.; Gravato, C.; Quintaneiro, C.; Golovko, O.; Žlábek, V.; Barata, C.; Soares, A.M.V.M.; Pestana, J.L.T. Life history and biochemical effects of chlorantraniliprole on Chironomus riparius. Sci. Total Environ. 2015, 508, 506-513. [CrossRef] [PubMed]

36. Ribeiro, M.J.; Maria, V.; Soares, A.M.V.M.; Scott-Fordsmand, J.J.; Amorim, M.J.B. Fate and Effect of Nano Tungsten Carbide Cobalt (WCCo) in the Soil Environment: Observing a Nanoparticle Specific Toxicity in Enchytraeus crypticus. Environ. Sci. Technol. 2018, 52, 11394-11401. [CrossRef] [PubMed]

37. Choudhury, N. Ecotoxicology of Aquatic System: A Review on Fungicide Induced Toxicity in Fishes. Pro Aqua Farm Mar. Biol. 2018, 1, 180001.

38. EFSA. Conclusion on the Peer Review of the Pesticide Risk Assessment of the Active Substance Disodium Phosphonate. EFSA J. 2013, 11, 3213. [CrossRef]

39. Baudy, P.; Zubrod, J.P.; Konschak, M.; Weil, M.; Schulz, R.; Bundschuh, M. Does long-term fungicide exposure affect the reproductive performance of leaf-shredders? A partial life-cycle study using Hyalella azteca. Environ. Pollut. 2017, 222, 458-464. [CrossRef]

40. Ahmad, F.; Ali, S.; Richardson, M.K. Effect of pesticides and metals on zebrafish embryo development and larval locomotor activity. bioRxiv 2020. [CrossRef]

41. Colosio, C.; Tiramani, M.; Maroni, M. Neurobehavioral Effects of Pesticides: State of the Art. Neurotoxicology 2003, 24, 577-591. [CrossRef]

42. Bjørling-Poulsen, M.; Andersen, H.R.; Grandjean, P. Potential developmental neurotoxicity of pesticides used in Europe. Environ. Health A Glob. Access Sci. Source 2008, 7, 1-22. [CrossRef] [PubMed]

43. Fenn, M.E.; Coffey, M.D. Studies on the In Vitro and In Vivo Antifungal Activity of Fosetyl-Al and Phosphorous Acid. Phytopathology 1984, 74, 606-611. [CrossRef]

44. Smillie, R. The Mode of Action of Phosphite: Evidence for Both Direct and Indirect Modes of Action on Three Phytophthora spp. in Plants. Phytopathology 1989, 79, 921. [CrossRef]

45. Almeida, A.R.; Salimian, M.; Ferro, M.; Marques, P.A.; Goncalves, G.; Titus, E.; Domingues, I. Biochemical and behavioral responses of zebrafish embryos to magnetic graphene/nickel nanocomposites. Ecotoxicol. Environ. Saf. 2019, 186, 109760. [CrossRef]

46. Abe, F.R.; Soares, A.M.V.M.; de Oliveira, D.P.; Gravato, C. Toxicity of dyes to zebrafish at the biochemical level: Cellular energy allocation and neurotoxicity. Environ. Pollut. 2018, 235, 255-262. [CrossRef]

47. Freitas, J.S.; Girotto, L.; Goulart, B.V.; Alho, L.D.O.G.; Gebara, R.C.; Montagner, C.C.; Schiesari, L.; Espíndola, E.L.G. Effects of 2,4-D-based herbicide $\left(\mathrm{DMA}^{\circledR}\right.$ 806) on sensitivity, respiration rates, energy reserves and behavior of tadpoles. Ecotoxicol. Environ. Saf. 2019, 182, 109446. [CrossRef]

48. Yu, B.P. Cellular defenses against damage from reactive oxygen species. Physiol. Rev. 1994, 74, 139-162. [CrossRef] [PubMed]

49. Nunes, M.E.M.; Müller, T.E.; Murussi, C.; do Amaral, A.M.B.; Gomes, J.L.C.; Marins, A.T.; Leitemperger, J.; Rodrigues, C.C.R.; Fiuza, T.L.; Costa, M.D.; et al. Oxidative effects of the acute exposure to a pesticide mixture of cypermethrin and chlorpyrifos on carp and zebrafish-A comparative study. Comp. Biochem. Physiol. Part C Toxicol. Pharmacol. 2018, 206-207, 48-53. [CrossRef] [PubMed]

50. Almroth, B.C.; Sturve, J.; Berglund, Å.; Förlin, L. Oxidative damage in eelpout (Zoarces viviparus), measured as protein carbonyls and TBARS, as biomarkers. Aquat. Toxicol. 2005, 73, 171-180. [CrossRef]

51. De Menezes, C.C.; Leitemperger, J.; Santi, A.; Lópes, T.; Aline Veiverberg, C.; Peixoto, S.; Bohrer Adaime, M.; Zanella, R.; Vargas Barbosa, N.B.; Lucia Loro, V. The effects of diphenyl diselenide on oxidative stress biomarkers in Cyprinus carpio exposed to herbicide quinclorac $\left(\right.$ Facet $^{\circledR}$ ). Ecotoxicol. Environ. Saf. 2012, 81, 91-97. [CrossRef] [PubMed]

52. Yonar, M.E. Protective effect of lycopene on oxidative stress and antioxidant status in Cyprinus carpio during cypermethrin exposure. Environ. Toxicol. 2013, 28, 609-616. [CrossRef]

53. Steevens, J.A.; Benson, W.H. Toxicological interactions of chlorpyrifos and methyl mercury in the amphipod, Hyalella azteca. Toxicol. Sci. 1999, 52, 168-177. [CrossRef] [PubMed]

54. McLoughlin, N.; Yin, D.; Maltby, L.; Wood, R.M.; Yu, H. Evaluation of sensitivity and specificity of two crustacean biochemical biomarkers. Environ. Toxicol. Chem. 2000, 19, 2085-2092. [CrossRef] 
55. Thompson, H.M. Esterases as Markers of Exposure to Organophosphates and Carbamates. Ecotoxicology 1999, 8, 369-384. [CrossRef]

56. Bicho, R.C.; Santos, F.; Gonçalves, M.; Soares, A.; Amorim, M. Enchytraeid Reproduction TestPLUS: Hatching, growth and full life cycle test-an optional multi-endpoint test with Enchytraeus crypticus. Ecotoxicology 2015, 24, 1053-1063. [CrossRef] [PubMed]

57. Guimarães, B.; Maria, V.L.; Römbke, J.; Amorim, M.J.B. Multigenerational exposure of Folsomia candida to ivermectin-Using avoidance, survival, reproduction, size and cellular markers as endpoints. Geoderma 2019, 337, 273-279. [CrossRef]

58. Gomes, S.I.L.; Scott-Fordsmand, J.J.; Amorim, M.J.B. Alternative test methods for (nano)materials hazards assessment: Challenges and recommendations for regulatory preparedness. NanoToday 2021, 40, 101242. [CrossRef]

59. Amorim, M.; Fernández-Cruz, M.L.; Hund-Rinke, K.; Scott-Fordsmand, J.J. Environmental hazard testing of nanobiomaterials. Environ. Sci. Eur. 2020, 32, 101. [CrossRef]

60. Amorim, M.J.B.; Scott-Fordsmand, J.J. Plastic pollution-A case study with Enchytraeus crypticus-From micro-to nanoplastics. Environ. Pollut. 2021, 271, 116363. [CrossRef] [PubMed] 